ARTICLE

https://doi.org/10.1038/s41467-020-18891-x

\title{
Preparation of nickel-iron hydroxides by microorganism corrosion for efficient oxygen evolution
}

Huan Yang ${ }^{1}$, Lanqian Gong${ }^{1}$, Hongming Wang (D) ${ }^{2}$, Chungli Dong ${ }^{3}$, Junlei Wang ${ }^{1}$, Kai Qi', Hongfang Liu (D) 1, Xingpeng Guo ${ }^{1} \&$ Bao Yu Xia (1) ${ }^{1 凶}$

Nickel-iron composites are efficient in catalyzing oxygen evolution. Here, we develop a microorganism corrosion approach to construct nickel-iron hydroxides. The anaerobic sulfate-reducing bacteria, using sulfate as the electron acceptor, play a significant role in the formation of iron sulfide decorated nickel-iron hydroxides, which exhibit excellent electrocatalytic performance for oxygen evolution. Experimental and theoretical investigations suggest that the synergistic effect between oxyhydroxides and sulfide species accounts for the high activity. This microorganism corrosion strategy not only provides efficient candidate electrocatalysts but also bridges traditional corrosion engineering and emerging electrochemical energy technologies.

\footnotetext{
${ }^{1}$ Key Laboratory of Material Chemistry for Energy Conversion and Storage (Ministry of Education), Hubei Key Laboratory of Material Chemistry and Service Failure, Wuhan National Laboratory for Optoelectronics, School of Chemistry and Chemical Engineering, Huazhong University of Science and Technology (HUST), 1037 Luoyu Road, Wuhan 430074, China. ${ }^{2}$ Institute for Advanced Study, Nanchang University, 999 Xuefu Road, Nanchang, China. ${ }^{3}$ Department of

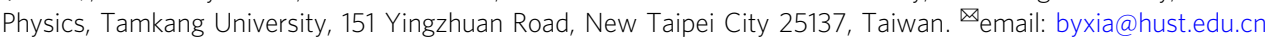


O xygen evolution is of great significance in several energy conversion systems including rechargeable metal-air batteries and water electrolysis devices ${ }^{1-4}$. However, the sluggish kinetics in the complicated multiple proton/electronprocesses requires highly efficient electrocatalysts ${ }^{5,6}$. Noble metal ( $\mathrm{Ru}$, Ir, etc.) based nanocomposites manifest high activities, but the limited earth reserves and high cost cannot support their practical applications. Numerous earth-abundant alternatives including metal (hydro)oxides and sulfides have been developed to replace precious electrocatalysts ${ }^{7-15}$. Among them, Ni-Fe oxides/hydroxides have been demonstrated as the excellent electrocatalysts for oxygen evolution in alkaline electrolytes ${ }^{15-17}$.

Various methods including electrodeposition and hydrothermal treatment have been developed to prepare $\mathrm{Ni}-\mathrm{Fe}$ oxides/ hydroxides ${ }^{18,19}$. These bottom-up methods require the meticulous treatment of the complex precursor at stringent synthetic conditions (high temperature, voltage or pressure) to realize the precise construction of nanostructures ${ }^{20-23}$. Generally, metal etching is a common phenomenon occurred at ambient temperature and pressure in corrosion engineering. Thus, this top-down approach by etching metallic substrates provides new opportunities to build the integrated electrodes at mild environment $^{24-27}$. Moreover, natural microbial usually promote the corrosion behaviors and bring the incorporation of heteroatom species. For example, the main corrosion products on carbon steel are iron sulfides and iron (hydroxy)oxides in the presence of sulfate reducing bacteria $(\mathrm{SRB})^{28}$. These corrosion products containing metal sulfides/(hydro)oxides have potential activity for oxygen evolution ${ }^{29-31}$. Nevertheless, few studies have focused on this natural microorganism corrosion induced biofilm electrodes.

Inspired by the natural microorganism-assisted corrosion behaviors occurred on pipeline and equipment in oil fields, here we demonstrate the preparation of highly active Ni-Fe composites by corrosion engineering in the presence of anaerobic SRB. The as-prepared electrode exhibits excellent activity for oxygen evolution with an overpotential of only $220 \mathrm{mV}$ needed to achieve the benchmark current density of $10 \mathrm{~mA} \mathrm{~cm}^{-2}$. Experimental and theoretical studies suggest that the synergistic effect between oxyhydroxide from chemical corrosion and iron sulfide species from microorganism corrosion would account for the high activity. This work not only provides an efficient alternative electrocatalyst but also more importantly introduces a facile corrosion strategy, which would attract broad interest from multidisciplinary fields of natural biology, traditional metal corrosion and modern electrochemical energy technologies.

\section{Results}

Formation and structural characterization of corrosion electrodes. Fig. 1a illustrates the formation process of iron sulfides decorated nickel-iron hydroxide $\left(\mathrm{Ni}(\mathrm{Fe})(\mathrm{OH})_{2}-\mathrm{FeS}_{x}\right)$ biofilm in the SRB-involved corrosion system. The color of Ni foam turns gradually from gray to black with the increase of corrosion time in the SRB solution, and the corrosion electrodes can be prepared with different scales (Supplementary Fig. 1). Generally, SRB consume the atomic hydrogen absorbed $\left(\mathrm{H}_{\mathrm{ads}}\right)$ at the cathode and reduce sulfates to sulfides. Finally, the reaction between sulfides from SRB metabolism and the dissolved nickel species simultaneously leads to the formation of $\mathrm{Ni}(\mathrm{Fe})(\mathrm{OH})_{2}-\mathrm{FeS}_{x}$. The corrosion mechanisms are described as follows: the dissolution of $\mathrm{Ni}$ foam $\left(\mathrm{Ni} \rightarrow \mathrm{Ni}^{2+}+2 \mathrm{e}^{-}\right)$and the process of SRB metabolism $\left(2 \mathrm{H}_{2} \mathrm{O}+2 \mathrm{e}^{-} \rightarrow 2 \mathrm{H}_{\mathrm{ads}}+2 \mathrm{OH}^{-} ; \mathrm{SO}_{4}{ }^{2-}+8 \mathrm{H}_{\mathrm{ads}} \rightarrow \mathrm{S}^{2-}+4 \mathrm{H}_{2} \mathrm{O}\right.$; $\mathrm{Fe}^{2+}+\mathrm{S}^{2-} \rightarrow \mathrm{FeS}$ ), and then the formation of final SRB corrosion-formed biofilm on the $\mathrm{Ni}$ foam $\left(\mathrm{Ni}^{2+}+\mathrm{Fe}^{2+}+2 \mathrm{OH}^{-}\right.$ $\left.+\mathrm{FeS} \rightarrow \mathrm{Ni}(\mathrm{Fe})(\mathrm{OH})_{2}-\mathrm{FeS}_{x}\right)$. Field-emission scanning electron microscopy (FESEM) image reveals the uniform nanosheet arrays deposited onto the skeleton of Ni foam (Fig. 1b). Transmission electron microscopy (TEM) image of the corrosion biofilm shows a highly rippled nanosheet structure (Fig. 1c). High-resolution (HR)TEM images indicate an average thickness of $\sim 5 \mathrm{~nm}$ for these nanosheets with an interplanar spacing of $0.25 \mathrm{~nm}$, corresponding to the (111) plane of $\alpha-\mathrm{Ni}(\mathrm{OH})_{2}$ phase (Fig. 1d, e). These morphology and microstructure features of the $\mathrm{Ni}(\mathrm{Fe})$ $(\mathrm{OH})_{2}-\mathrm{FeS}_{x}$ corrosion biofilm are similar to the corrosion products of $\mathrm{Ni}(\mathrm{Fe})(\mathrm{OH})_{2}$ obtained in the absence of SRB (Supplementary Fig. 2). Compared with the selected-area electron diffraction (SAED) pattern of $\mathrm{Ni}(\mathrm{Fe})(\mathrm{OH})_{2}$ (Supplementary Fig. 2b), more distinct diffraction rings suggest the enhanced crystallinity of $\mathrm{Ni}(\mathrm{Fe})(\mathrm{OH})_{2}-\mathrm{FeS}_{x}$ with the incorporation of $\mathrm{Fe}-\mathrm{S}$ species (Fig. 1c). The elemental mappings show that $\mathrm{Fe}$ and $\mathrm{S}$ species are homogeneously distributed on the surface of $\mathrm{Ni}(\mathrm{Fe})$ $(\mathrm{OH})_{2}-\mathrm{FeS}_{x}$ product (Fig. 1f). The atomic ratio of $\mathrm{Ni}, \mathrm{O}, \mathrm{Fe}$ and $\mathrm{S}$ elements is close to 32:64:2:1 (Supplementary Fig. 3). While only $\mathrm{Ni}, \mathrm{O}$ and $\mathrm{Fe}$ elements appear evenly in the $\mathrm{Ni}(\mathrm{Fe})(\mathrm{OH})_{2}$ nanosheets (Supplementary Fig. 2d), indicating that S element is not doped into the chemical corrosion product. A short electrochemical activation process promotes the transformation of hydroxides to oxyhydroxides. SEM and TEM images show that the $\mathrm{Ni}(\mathrm{Fe}) \mathrm{OOH}-\mathrm{FeS}_{x}$ electrode remains the uniform nanosheet arrays (Fig. 2a, b). HRTEM images display the interplanar spacing of $0.24 \mathrm{~nm}$ corresponded to the (101) plane of $\alpha-\mathrm{NiOOH}$ phase (Fig. 2c, d), which suggests the conversion of $\alpha-\mathrm{Ni}(\mathrm{Fe})(\mathrm{OH})_{2}$ to $\alpha$ $\mathrm{Ni}(\mathrm{Fe}) \mathrm{OOH}$. The elemental distribution verifies that $\mathrm{Fe}$ and $\mathrm{S}$ elements still exist on the surface of corrosion-formed biofilm (Fig. 2e). Combined with the X-ray diffraction (XRD) analysis (Supplementary Fig. 4), the diffraction peaks at $33^{\circ}$ and $46^{\circ}$ for $\mathrm{Ni}$ $(\mathrm{Fe})(\mathrm{OH})_{2}-\mathrm{FeS}_{x}$ are related to $\alpha-\mathrm{Ni}(\mathrm{OH})_{2}$ (JCPDS: 38-0715), while the peaks at $28^{\circ}$ and $58^{\circ}$ for $\mathrm{Ni}(\mathrm{Fe}) \mathrm{OOH}-\mathrm{FeS}_{x}$ are corresponding to $\alpha-\mathrm{NiOOH}$ (JCPDS: 27-0956). These results are consistent with the structural evolution by TEM observations (Figs. 1 and 2). Furthermore, more distinct SAED rings (Fig. 2b inset) and higher XRD intensity of $\mathrm{Ni}(\mathrm{Fe}) \mathrm{OOH}-\mathrm{FeS}_{x}$ suggest the improved crystallinity of corrosion product after the activation.

Compositional analysis of corrosion products. The formation of $\mathrm{Fe}-\mathrm{S}$ species in SRB-corrosion products is then verified by Raman spectra at 310 and $358 \mathrm{~cm}^{-1}$, which are assigned to the typical mackinawite FeS phase (Fig. 3a) ${ }^{32}$. To distinguish the respective effects of microbial metabolism and chemical corrosion on the corroded Ni foam, the presence of Raman peaks at 280-310 and $350-370 \mathrm{~cm}^{-1}$ also verify the formation of $\mathrm{Fe}-\mathrm{S}$ species on the surface of $\mathrm{Ti}$ substrates treated in the SRB medium (Supplementary Fig. 5). Moreover, the peaks at 460, 529 and $690 \mathrm{~cm}^{-1}$ are respectively attributed to the $\mathrm{A}_{\mathrm{lg}}$ stretching mode of $\mathrm{Ni}-\mathrm{OH}$, $\mathrm{Ni}-\mathrm{O}$ and $\mathrm{Fe}-\mathrm{O}$ in the $\mathrm{Ni}(\mathrm{Fe})(\mathrm{OH})_{2}-\mathrm{FeS}_{x}$ (Fig. 3a) ${ }^{18}$. After a short activation process, Raman peaks at 479 and $560 \mathrm{~cm}^{-1}$ match well with the $e_{g}$ bending vibration and $\mathrm{A}_{1 \mathrm{~g}}$ stretching vibration of $\mathrm{Ni}-\mathrm{O}$ in the $\mathrm{Ni}(\mathrm{Fe}) \mathrm{OOH}-\mathrm{FeS}_{x}$, and the $\mathrm{FeS}$ phase is still preserved (Fig. 3a) ${ }^{33}$. However, the $\mathrm{Ni}-\mathrm{O}$ peaks are sharpened, and the vibrations assigned to $\mathrm{Fe}-\mathrm{S}$ in the $\mathrm{Ni}(\mathrm{Fe})$ $\mathrm{OOH}-\mathrm{FeS}_{x}$ are significantly shifted and broadened (Fig. 3a), indicating the enhanced crystallinity of corrosion product after the activation, which is consistent with the analysis of XRD and TEM (Fig. 2, Supplementary Fig. 4). The surface composition of corrosion product is further investigated by X-ray photoelectron spectroscopy (XPS). It is confirmed that the Fe-S species only exists in the SRB-involved corrosion product (Fig. 3b, Supplementary Fig. $5 \mathrm{c}$ ). The deconvoluted $\mathrm{O} 1 \mathrm{~s}$ spectrum can be fitted into $\mathrm{M}(\mathrm{Ni} / \mathrm{Fe})-\mathrm{O}, \mathrm{M}-\mathrm{O}-\mathrm{H}$ and $\mathrm{H}_{2} \mathrm{O}$ (Fig. 3c, Supplementary Fig. $5 \mathrm{~d}$ ). In the $\mathrm{S} 2 p$ spectrum, two peaks at 162.1 and $168.4 \mathrm{eV}$ are indexed to the $\mathrm{M}-\mathrm{S}$ and $\mathrm{S}-\mathrm{O}$, respectively (Fig. $3 \mathrm{~d}$ ). The S $2 p$ 

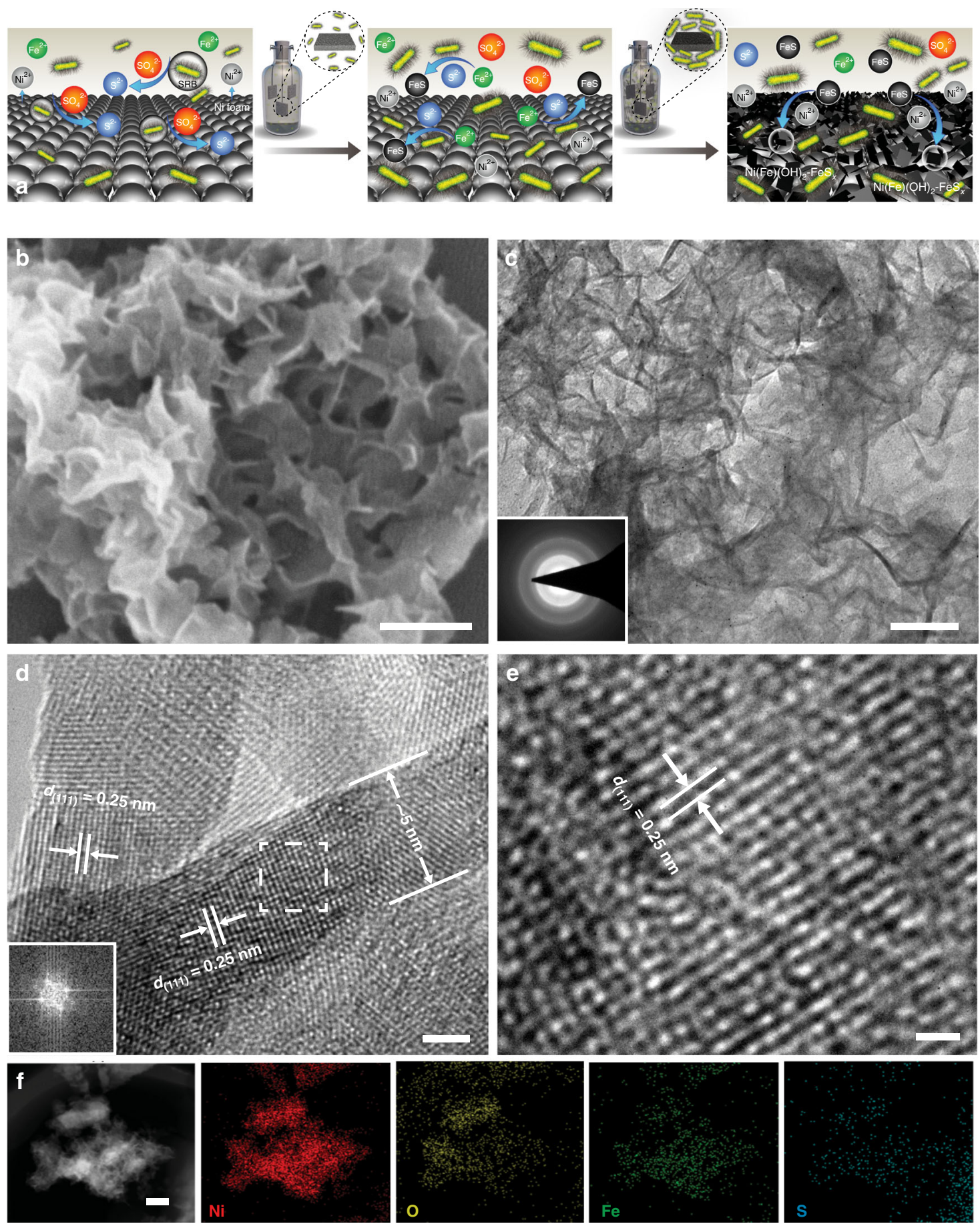

Fig. 1 Formation and structural characterizations of $\mathbf{N i}(\mathbf{F e})(\mathbf{O H})_{\mathbf{2}}-\mathbf{F e S}_{\mathbf{x}}$ a Preparation scheme of the SRB-assisted corrosion-formed electrode. $\mathbf{b}$ FESEM image, scale bar: $200 \mathrm{~nm}$. c TEM image and corresponding SAED pattern (inset), scale bar: $50 \mathrm{~nm}$. d, e HRTEM images and corresponding fast Fourier transform (FFT) pattern (inset in d), scale bars: $2 \mathrm{~nm}$ (d) and $1 \mathrm{~nm}(\mathbf{e}) . \mathbf{f}$ corresponding elemental mappings, scale bar: $250 \mathrm{~nm}$.

peak only exists in the SRB-corrosion products (Supplementary Fig. 5e). Fe 2p regions can be fitted into two pairs of characteristic peaks accompanied with the satellite peaks (Fig. 3e, Supplementary Fig. 5f), which are attributed to the coexistence of $\mathrm{Fe}(\mathrm{II})\left(2 p_{3 /}\right.$ 2 at $710 \mathrm{eV}$ and $2 p_{1 / 2}$ at $\left.721 \mathrm{eV}\right)$ and $\mathrm{Fe}(\mathrm{III})\left(2 p_{3 / 2}\right.$ at $714 \mathrm{eV}$ and $2 p_{1 / 2}$ at $\left.724 \mathrm{eV}\right)^{34}$. The Ni $2 p$ spectrum can be respectively fitted into a pair of peaks with $\mathrm{Ni} 2 p_{3 / 2}$ at $854 \mathrm{eV}$ and $\mathrm{Ni} 2 p_{1 / 2}$ at $872 \mathrm{eV}$ (Fig. 3f), which can be assigned to $\mathrm{Ni}(\mathrm{II})^{35}$. After the activation, the deconvoluted $\mathrm{O} 1 \mathrm{~s}$ spectrum of $\mathrm{Ni}(\mathrm{Fe}) \mathrm{OOH}-\mathrm{FeS}_{x}$ shows the obviously increased area ratio of M-O to M-OH (Fig. 3c), and the emerged $\mathrm{Ni} 2 p_{3 / 2}(856 \mathrm{eV})$ and $\mathrm{Ni} 2 p_{1 / 2}(874 \mathrm{eV})$ peaks are related to $\mathrm{NiOOH}$ (Fig. 3f) ${ }^{36,37}$. Moreover, the peak assigned to $\mathrm{S}-\mathrm{O}$ in the $\mathrm{S} 2 p$ spectrum of $\mathrm{Ni}(\mathrm{Fe})(\mathrm{OOH})-\mathrm{FeS}_{x}$ is shifted and weakened. All the above results suggest the oxidative transformation of $\mathrm{Ni}$ $(\mathrm{Fe})(\mathrm{OH})_{2}-\mathrm{FeS}_{x}$ to $\mathrm{Ni}(\mathrm{Fe}) \mathrm{OOH}-\mathrm{FeS}_{x}$, which is verified by the structural characteristics (Figs. 2 and 3$)^{38}$.

$\mathrm{X}$-ray absorption fine structure analysis of corrosion products. The structural properties of $\mathrm{Ni}(\mathrm{Fe})(\mathrm{OH})_{2}-\mathrm{FeS}_{x}$ and $\mathrm{Ni}(\mathrm{Fe})$ $\mathrm{OOH}-\mathrm{FeS}_{x}$ are further studied by X-ray absorption fine structure (XAFS). The Fe $K$-edge X-ray absorption near edge structure (XANES) shows that the $\mathrm{Fe}(\mathrm{II})$ and $\mathrm{Fe}(\mathrm{III})$ species coexist in the 

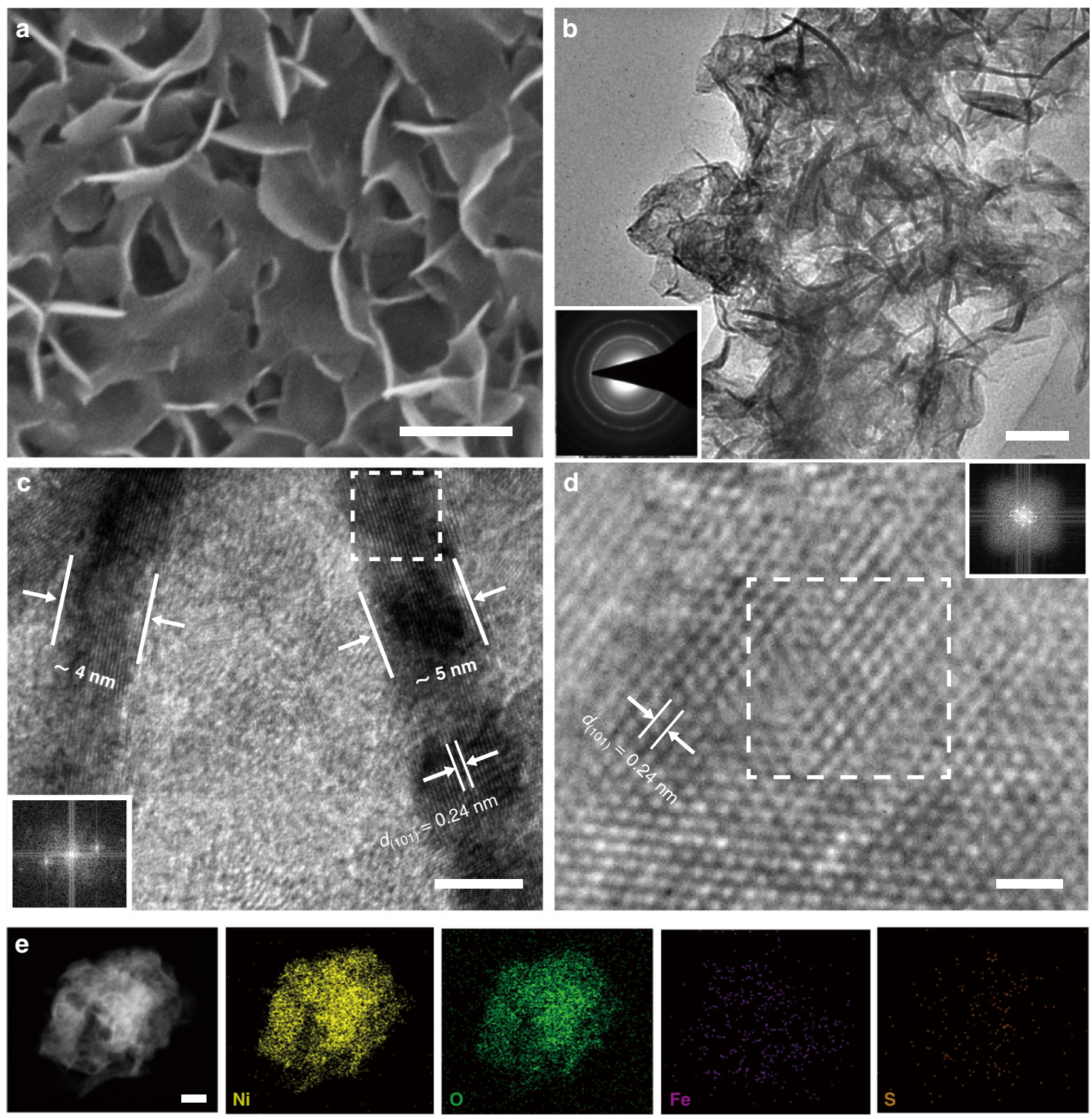

Fig. 2 Structural characterizations of $\mathbf{N i ( F e ) O O H - F e S}$. a FESEM image, scale bar: $200 \mathrm{~nm}$. b TEM image and corresponding SAED pattern (inset), scale bar: $50 \mathrm{~nm}$. c, d HRTEM images and corresponding FFT patterns (insets), scale bars: $5 \mathrm{~nm}$ (c) and $1 \mathrm{~nm}$ (d). e corresponding elemental mappings, scale bar: $50 \mathrm{~nm}$.

$\mathrm{Ni}(\mathrm{Fe})(\mathrm{OH})_{2}-\mathrm{FeS}_{x}$ and $\mathrm{Ni}(\mathrm{Fe}) \mathrm{OOH}-\mathrm{FeS}_{x}$. Notably, the intensity of main absorption peak of $\mathrm{Ni}(\mathrm{Fe}) \mathrm{OOH}-\mathrm{FeS}_{x}$ exceeds that of $\mathrm{Ni}$ $(\mathrm{Fe})(\mathrm{OH})_{2}-\mathrm{FeS}_{x}$, and the energy of the rising edge is higher in the former, which suggests that a higher oxidation state of $\mathrm{Fe}$ in the activated $\mathrm{Ni}(\mathrm{Fe}) \mathrm{OOH}-\mathrm{FeS}_{x}$ (Fig. $4 \mathrm{a}$ ). The $\mathrm{Fe}-\mathrm{Fe} / \mathrm{Ni}$ and $\mathrm{Fe}-\mathrm{O} / \mathrm{S}$ bonds of $\mathrm{Ni}(\mathrm{Fe})(\mathrm{OH})_{2}-\mathrm{FeS}_{x}$ and $\mathrm{Ni}(\mathrm{Fe}) \mathrm{OOH}-\mathrm{FeS}_{x}$ are verified by the Fe $R$-space extended X-ray absorption fine structure (EXAFS) profiles (Fig. 4b). Compared with the larger coordination number $(\mathrm{CN})$ of $\mathrm{Fe}-\mathrm{O}, \mathrm{Fe}-\mathrm{S}$ and $\mathrm{Fe}-\mathrm{Ni}$ in the $\mathrm{Ni}(\mathrm{Fe}) \mathrm{OOH}-\mathrm{FeS}_{\mathrm{x}}\left(\mathrm{CN}_{\mathrm{Fe}-\mathrm{O}}\right.$ $\left.=2.9, \mathrm{CN}_{\mathrm{Fe}-\mathrm{S}}=2.6, \mathrm{CN}_{\mathrm{Fe}-\mathrm{Ni}}=4.7\right), \mathrm{Ni}(\mathrm{Fe})(\mathrm{OH})_{2}-\mathrm{FeS}_{x}$ shows smaller $\mathrm{CN}_{\mathrm{Fe}-\mathrm{O}}$ (1.7), $\mathrm{CN}_{\mathrm{Fe}-\mathrm{S}}$ (1.0) and $\mathrm{CN}_{\mathrm{Fe}-\mathrm{Ni}}$ (1.8) (Fig. 4c, Supplementary Table 2), indicating the defective local atomic structural and distortion in the activated $\mathrm{Ni}(\mathrm{Fe}) \mathrm{OOH}-\mathrm{FeS}_{x}{ }^{39}$. The defective/distorted structure revealed by EXAFS is in accordance with the charge state determined by XANES analysis (Fig. 4a). Moreover, the presence of $\mathrm{Fe}-\mathrm{S}$ bonds in the $\mathrm{Ni}(\mathrm{Fe})(\mathrm{OH})_{2}-\mathrm{FeS}_{x}$ and $\mathrm{Ni}(\mathrm{Fe}) \mathrm{OOH}-\mathrm{FeS}_{x}$ is further confirmed by the $\mathrm{S} K$-edge XANES spectra (Fig. 4d). Compared with the initial $\mathrm{Ni}(\mathrm{Fe})$ $(\mathrm{OH})_{2}-\mathrm{FeS}_{x}$, the decreased content of $\mathrm{Fe}-\mathrm{S}$ and the enhanced content of $\mathrm{S}-\mathrm{O}$ in the $\mathrm{Ni}(\mathrm{Fe}) \mathrm{OOH}-\mathrm{FeS}_{x}$ suggest some partially oxidized S species. Nevertheless, most Fe-S species are preserved in the $\mathrm{Ni}(\mathrm{Fe}) \mathrm{OOH}-\mathrm{FeS}_{x}$.

Electrochemical performance of corrosion electrodes. The activation process is completed after only 10 cycles of cyclic voltammetry (CV) scans, which is associated with the phase transform from hydroxides to oxyhydroxides (Fig. 5a). The peak pair in the potential range of $1.25-1.50 \mathrm{~V}$ versus the reversible hydrogen electrode (vs. RHE) corresponds to the redox couple of $\mathrm{Ni}(\mathrm{II}) / \mathrm{Ni}(\mathrm{III})^{40}$. Fig. $5 \mathrm{~b}$ shows the $\mathrm{CV}$ curves of three electrodes after the activation process. For comparison, Fig. $5 \mathrm{c}$ shows the linear scan polarization curves for oxygen evolution over different electrodes. Among them, the blank Ni foam exhibits a similar activity (an overpotential $(\eta)$ of $400 \mathrm{mV}$ at $10 \mathrm{~mA} \mathrm{~cm}^{-2}$ ) to the commercial $\mathrm{IrO}_{2}$ catalyst (an $\eta$ of $370 \mathrm{mV}$ at $10 \mathrm{~mA} \mathrm{~cm}^{-2}$ ). After the corrosion treatment, the resultant $\mathrm{Ni}(\mathrm{Fe}) \mathrm{OOH}$ electrode demonstrates a significant enhancement in activity as it requires an $\eta$ of only $300 \mathrm{mV}$ to reach the current density of $10 \mathrm{~mA} \mathrm{~cm}^{-2}$. Remarkably, the microorganism-assisted corrosion-formed $\mathrm{Ni}$ $(\mathrm{Fe}) \mathrm{OOH}-\mathrm{FeS}_{x}$ electrode exhibits a greatly enhanced activity, 

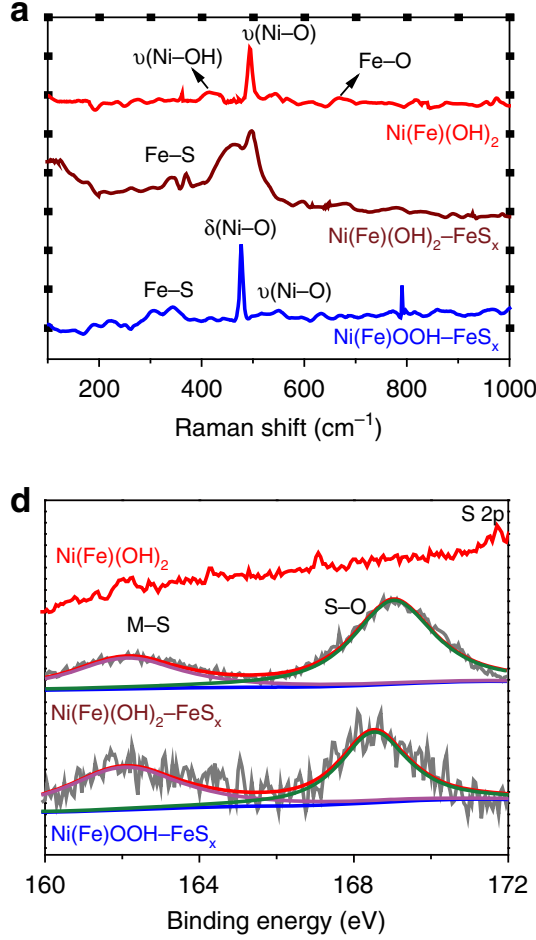

b

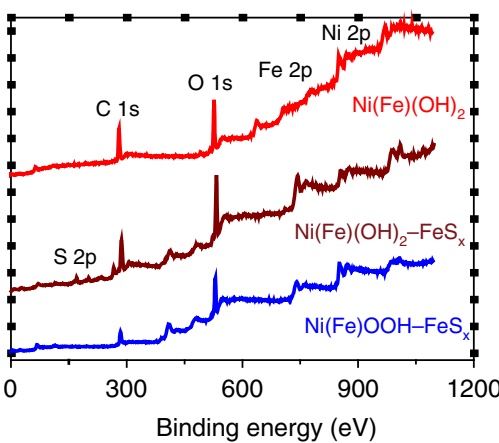

e

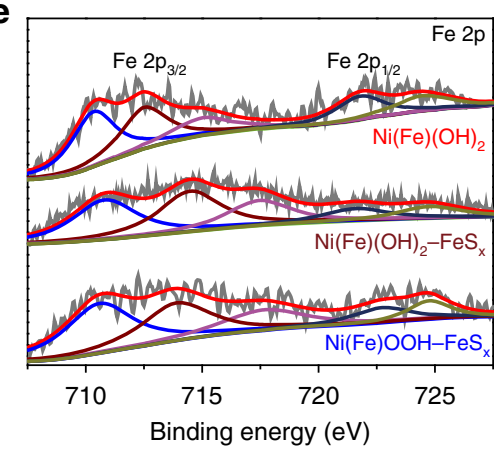

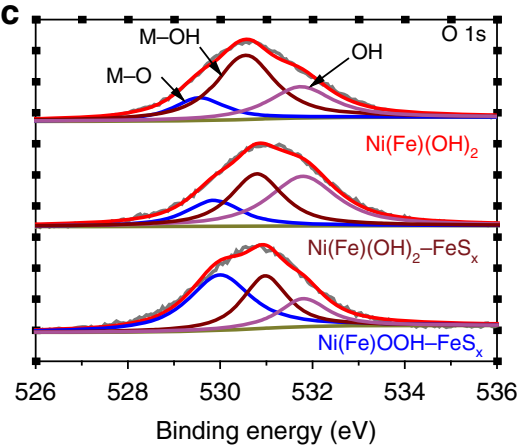

$\mathbf{f}$

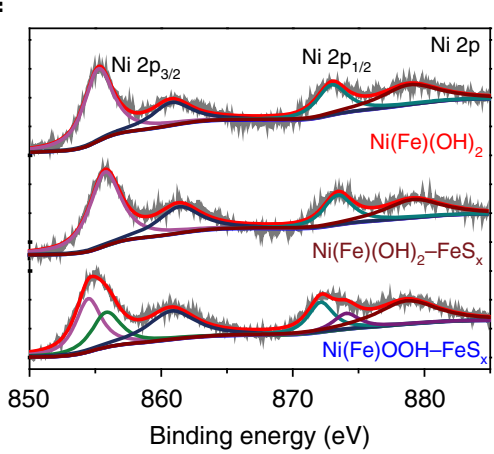

Fig. 3 Compositional characterizations of different corrosion-formed products. a Raman spectra, $\mathbf{b}$ XPS surveys, $\mathbf{c}-\mathbf{f}$ high-resolution XPS spectra of O $1 \mathrm{~s}$ (c), S $2 p(\mathbf{d})$, Fe $2 p(\mathbf{e})$ and $\mathrm{Ni} 2 p(\mathbf{f})$.

requiring an $\eta$ of only $220 \mathrm{mV}$ to achieve the current density of $10 \mathrm{~mA} \mathrm{~cm}^{-2}$. As seen in the corresponding Tafel plots (Fig. $5 \mathrm{~d}$ ), the $\mathrm{Ni}(\mathrm{Fe}) \mathrm{OOH}$ and $\mathrm{Ni}(\mathrm{Fe}) \mathrm{OOH}-\mathrm{FeS}_{x}$ electrodes respectively exhibit the Tafel slopes of 59 and $55 \mathrm{mV} \mathrm{dec}^{-1}$, which is much lower than that of the blank $\mathrm{Ni}$ foam electrode $\left(71 \mathrm{mV} \mathrm{dec}^{-1}\right)$ and $\mathrm{IrO}_{2}\left(80 \mathrm{mV} \mathrm{dec}^{-1}\right)$. Apparently, the $\mathrm{Ni}(\mathrm{Fe}) \mathrm{OOH}-\mathrm{FeS}_{x}$ electrode shows the most favorable kinetics for oxygen evolution. Compared to recent NiFe-based materials, this $\mathrm{Ni}(\mathrm{Fe}) \mathrm{OOH}-\mathrm{FeS}_{x}$ electrode shows a comparable performance for the oxygen evolution (Fig. 5e, Supplementary Table 3). The electrochemically active surface area (ECSA) is measured by the double-layer capacitance via CV curves in the double-layer region at different scan rates (Supplementary Fig. 6). Both calculated capacitances of $\mathrm{Ni}(\mathrm{Fe}) \mathrm{OOH}-\mathrm{FeS}_{x}\left(3.1 \mathrm{mF} \mathrm{cm}^{-2}\right)$ and $\mathrm{Ni}(\mathrm{Fe}) \mathrm{OOH}\left(2.3 \mathrm{mF} \mathrm{cm}^{-2}\right)$ are higher than that of the blank $\mathrm{Ni}$ electrode $\left(1.9 \mathrm{mF} \mathrm{cm}^{-2}\right)$. This suggests that the increased active sites and enhanced intrinsic activity of NiFe-based nanosheets play the dominant role in improving the activity. Electrochemical impedance spectroscopy (EIS) at $1.54 \mathrm{~V}$ is applied to further obtain the charge-transfer kinetics of the electrocatalytic process. The charge-transfer resistances $\left(R_{c t}\right)$ of the $\mathrm{Ni}(\mathrm{Fe}) \mathrm{OOH}-\mathrm{FeS}_{x}(2.2 \Omega)$ and $\mathrm{Ni}(\mathrm{Fe})$ $\mathrm{OOH}(10 \Omega)$ electrodes are much lower than that of the blank $\mathrm{Ni}$ foam electrode $(35 \Omega)$, suggesting the favorable charge transfer capability over these corrosion-formed electrodes (Supplementary Fig. 7a). Moreover, the $\mathrm{Ni}(\mathrm{Fe}) \mathrm{OOH}-\mathrm{FeS}_{x}$ electrode displays a high Faradaic efficiency of $97 \%$ for oxygen production (Supplementary Fig. $7 \mathrm{~b})$. The $\mathrm{Ni}(\mathrm{Fe}) \mathrm{OOH}-\mathrm{FeS}_{x}$ electrode can function steadily in $1.0 \mathrm{M} \mathrm{KOH}$ electrolyte for at least $16 \mathrm{~h}$ at constant current densities of $10 \mathrm{~mA} \mathrm{~cm}^{-2}$ at $\sim 1.45 \mathrm{~V}$ and $100 \mathrm{~mA} \mathrm{~cm}^{-2}$ at $\sim 1.53 \mathrm{~V}$ (Fig. 5f, Supplementary Movies 1-4). Furthermore, no significant structural changes are observed on the corrosionformed electrode after the stability test (Supplementary Fig. 8).

The effects of the SRB amount ( $V_{\mathrm{SRB}}, 23 \%, 33 \%$ and $65 \%$ ) and corrosion time (3-17 days) are investigated to monitor the corrosive environment (Supplementary Fig. 9). In general, the electrodes produced by simple chemical corrosion show enhanced performance, and the electrodes obtained by SRB-assisted corrosion show further enhanced performance (Supplementary Fig. 9f). For different SRB contents, a volume fraction $\left(V_{S R B}\right)$ of $33 \%$ appears most favorable to produce highly active electrodes. With different corrosion time, the electrocatalytic activity of electrodes first increases and then decreases. When the corrosion time is 10 days, the electrocatalytic activity reaches the optimum. FESEM images also verified the surface evolution over the corrosion process (Supplementary Fig. 10). Particularly, the amount of SRB on the corrosion-formed biofilm increases initially with the corrosion time from 3 days to 10 days. After that, the SRB gradually fall off the electrode surface, and the corrosion-formed biofilm becomes looser even cracked (Supplementary Fig. 11), which is generally consistent with the growth trend of SRB ${ }^{28}$. This microorganism-assisted strategy can be effectively extended to various metal substrates (Supplementary Fig. 12) and transition metal compounds (Supplementary Fig. 13).

Theoretical calculations into different electrodes. To provide further insights into the underlying mechanism for these highly efficient $\mathrm{Ni}(\mathrm{Fe}) \mathrm{OOH}-\mathrm{FeS}_{x}$ electrodes, some density functional theory (DFT) calculations are performed. The surface substitution of $S$ into transition-metal oxyhydroxides will enhance the electrocatalytic activity, thus the computations of $\mathrm{Fe}$ on the surface affected by the surrounding incorporation of $S$ are considered ${ }^{41,42}$. And the structures of $\mathrm{Ni}(\mathrm{Fe})(\mathrm{OH})_{2}-\mathrm{FeS}_{x}$ are constructed using the model developed by Friebel and coworkers $^{43}$. Specifically, the $\mathrm{O}$ atoms at the surface and subsurface of $\mathrm{Ni}(\mathrm{Fe})(\mathrm{OH})_{2}$ are replaced by the $\mathrm{S}$ atoms to form the $\mathrm{Fe}-\mathrm{S}$ species in $\mathrm{Ni}(\mathrm{Fe})(\mathrm{OH})_{2}-\mathrm{FeS}$, and $\mathrm{Ni}(\mathrm{Fe})(\mathrm{OH})_{2}-\mathrm{Fe}_{4} \mathrm{~S}_{12}$ is optimally built by replacing the $\mathrm{Fe}_{4} \mathrm{O}_{12}$ with $\mathrm{Fe}_{4} \mathrm{~S}_{12}$ cluster (Supplementary Figs. 14-16). After the activation, the protons and $\mathrm{S}$ species of $\mathrm{Ni}$ 

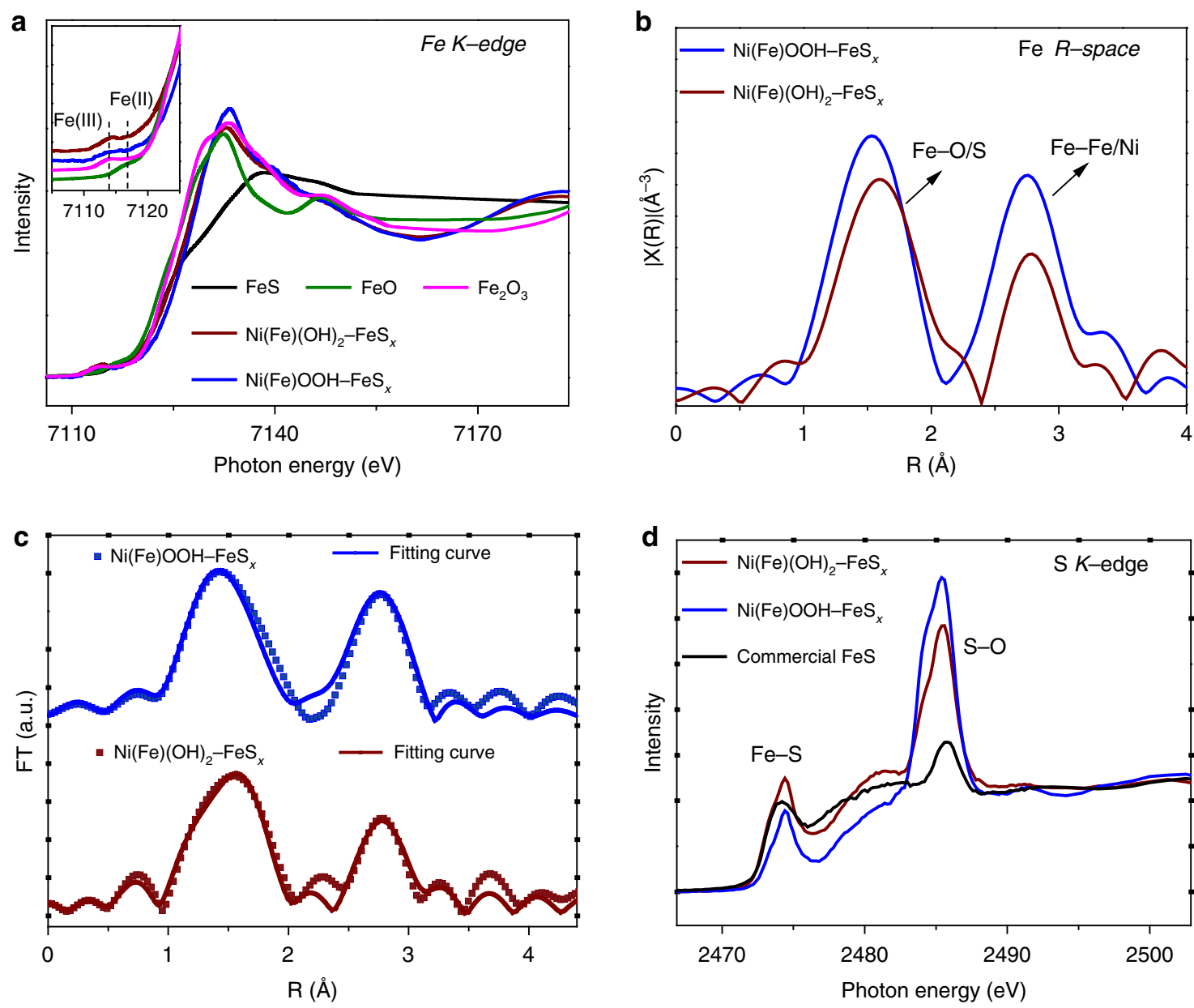

Fig. 4 XANES and EXAFS analysis of $\mathbf{N i}(\mathbf{F e})(\mathbf{O H})_{\mathbf{2}}-\mathbf{F e S}_{\mathbf{x}}$ and $\mathbf{N i ( F e ) O O H - F e S} \mathbf{S}_{\mathbf{x}}$ a Fe $K$-edge XANES spectra (inset shows the enlarged edge area), b Fe $R$ space EXAFS spectra, $\mathbf{c}$ the associated Fourier transforms and fitting curves of Fe $K$-edge EXAFS spectra, and $\mathbf{d} \mathrm{S} K$-edge XANES spectra.
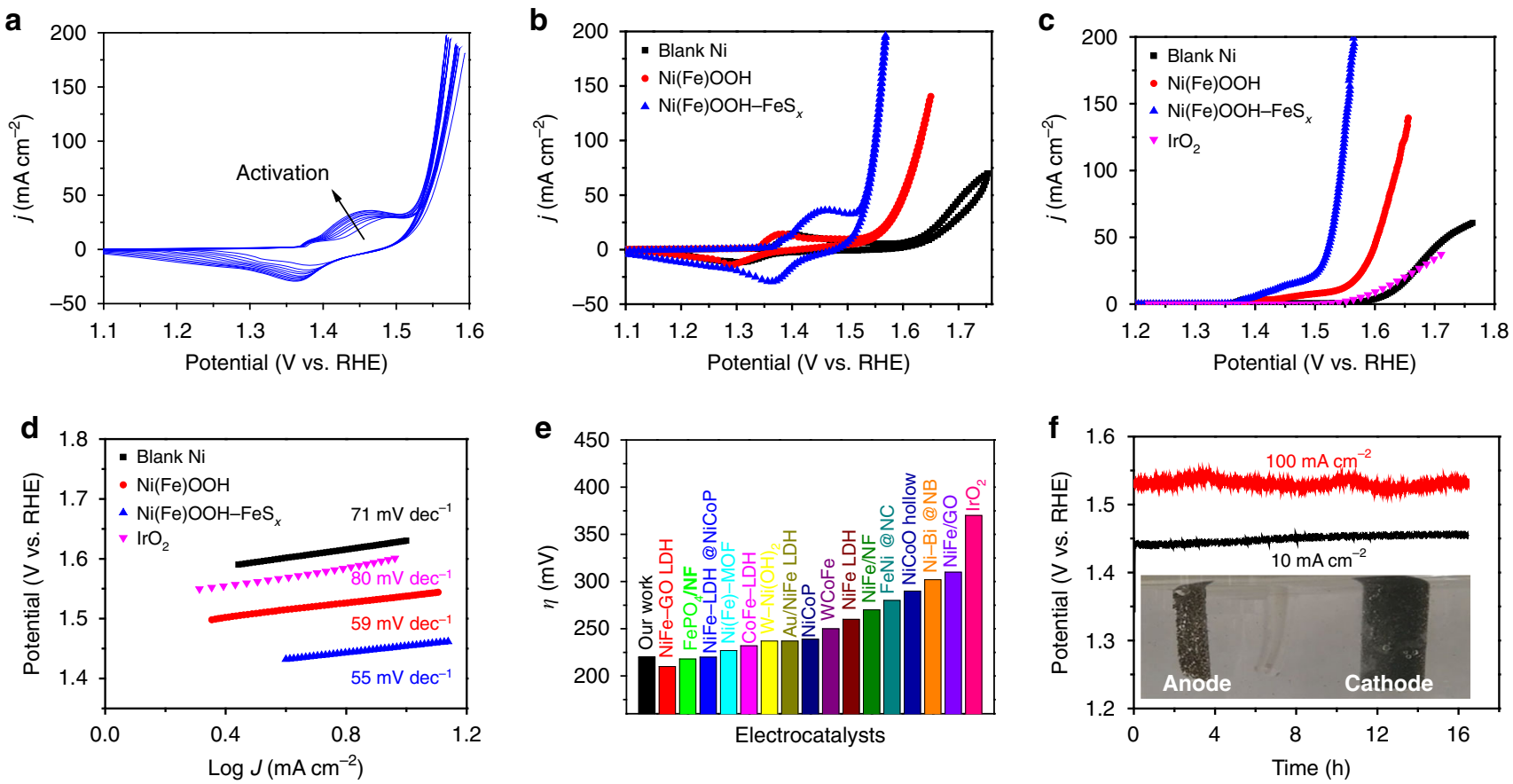

Fig. 5 Electrochemical measurements of different electrodes. a Activation $\mathrm{CV}$ curves of $\mathrm{Ni}(\mathrm{Fe}) \mathrm{OOH}-\mathrm{FeS}$. b $\mathrm{CV}$ profiles, c polarization curves, and $\mathbf{d}$ the corresponding Tafel plots of different electrodes, e activity comparison of recent NiFe-based electrocatalysts. $\mathbf{f}$ Chronopotentiometric curves of Ni(Fe) $\mathrm{OOH}-\mathrm{FeS}_{x}$ obtained at the constant current densities of 10 and $100 \mathrm{~mA} \mathrm{~cm}^{-2}$ (inset shows the three electrodes photograph). 

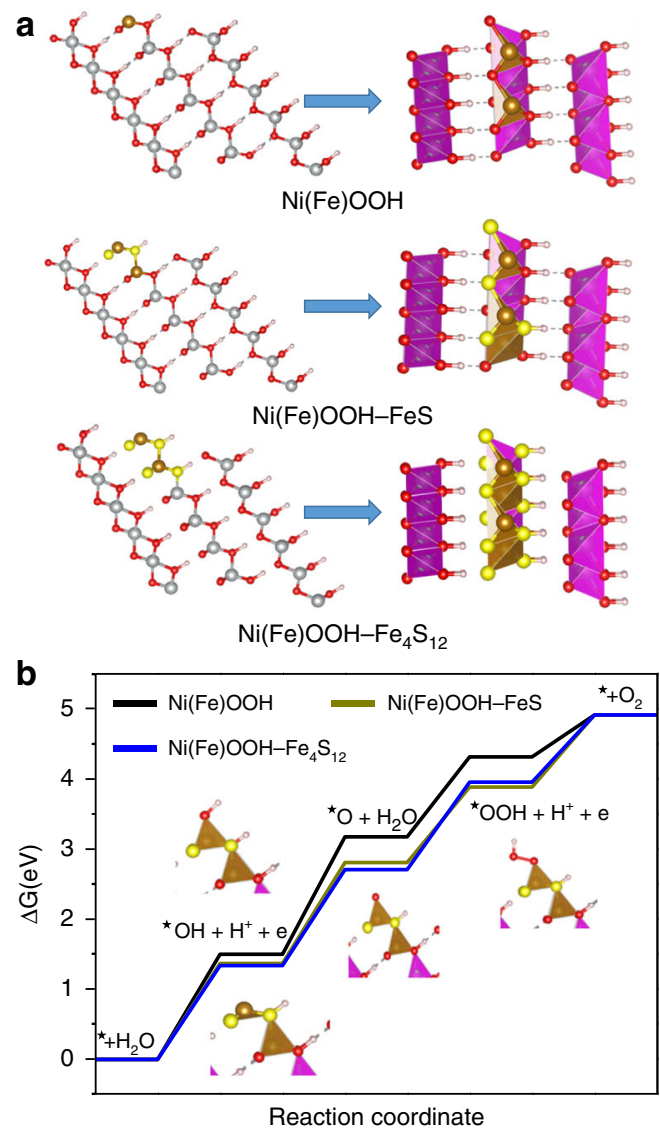
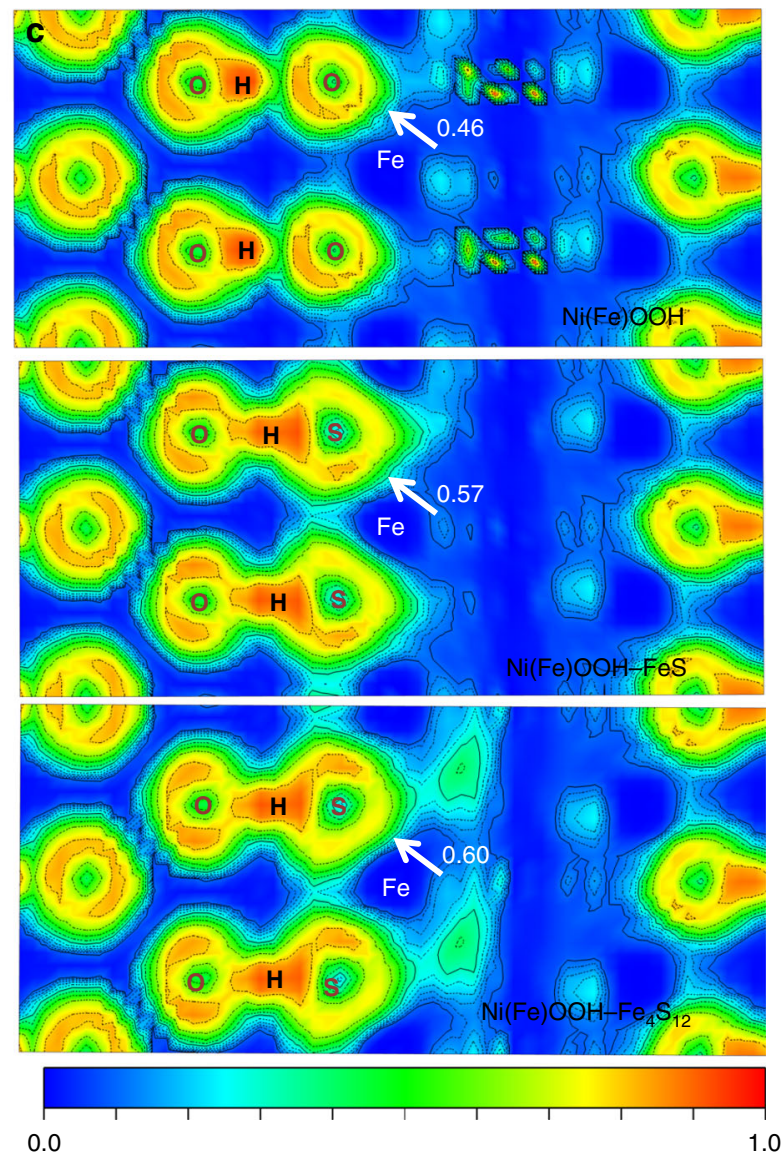

Fig. 6 DFT calculations. a Structural model, b free energy diagram, c electron localization function.

$(\mathrm{Fe})(\mathrm{OH})_{2}-\mathrm{FeS}_{x}$ are respectively subtracted and partially oxidized to form $\mathrm{Ni}(\mathrm{Fe}) \mathrm{OOH}-\mathrm{FeS}_{x}$ (Fig. 6a). A well-established four-step mechanism is employed to investigate the reaction kinetics. Thermodynamic analyses suggest that the formation of ${ }^{*} \mathrm{O}$ intermediate is the rate-determining step (RDS) on these corrosion electrodes (Fig. 6b, Supplementary Fig. 17a and Table 4). The surface oxidation simultaneously occurs on the $\mathrm{Ni}(\mathrm{Fe})(\mathrm{OH})_{2}$ during the electrochemical activation process, and the lower free energy gap between ${ }^{*} \mathrm{O}$ and ${ }^{*} \mathrm{OOH}$ will lead to a reduced $\eta$ of $\mathrm{Ni}$ $(\mathrm{Fe}) \mathrm{OOH}$ than that of the corresponding $\mathrm{Ni}(\mathrm{Fe})(\mathrm{OH})_{2}$, which means the oxygen evolution catalyzed by $\mathrm{Ni}(\mathrm{Fe}) \mathrm{OOH}$ will be more favorable than $\mathrm{Ni}(\mathrm{Fe})(\mathrm{OH})_{2}$ (Fig. 6b, Supplementary Table 4). Moreover, the incorporation of $\mathrm{S}$ into $\mathrm{Ni}(\mathrm{Fe})(\mathrm{OH})_{2}-\mathrm{FeS}_{\mathrm{x}}$ and $\mathrm{Ni}(\mathrm{Fe}) \mathrm{OOH}-\mathrm{FeS}_{x}$ will induce a further decreased free energy gap between ${ }^{*} \mathrm{O}$ and ${ }^{*} \mathrm{OOH}$ and lead to a reduced $\eta$ for the oxygen evolution (Supplementary Fig. 17a, b). As the increased S substitution on the surface of $\mathrm{Ni}(\mathrm{Fe}) \mathrm{OOH}$, the decreased free energy gap between $* \mathrm{OH}$ and ${ }^{*} \mathrm{O}$ will lead to a further reduced $\eta$ on the activated $\mathrm{Ni}(\mathrm{Fe}) \mathrm{OOH}-\mathrm{FeS}_{x}$ (Fig. 6b, Supplementary Table 4). These results suggest hydroxyl sulfide or sulfurized hydroxide would promote the oxygen evolution on the $\mathrm{Ni}(\mathrm{Fe})$ $\mathrm{OOH}-\mathrm{FeS}_{\mathrm{x}}$. By analyzing the density of state (DOS), it is found that the $\eta$ is correlated with the net charge of Fe (Supplementary Fig. 18, Table 5). Compared with the net charge of Fe (0.227) and Fermi level $(-2.46)$ of $\mathrm{Ni}(\mathrm{Fe})(\mathrm{OH})_{2}$, the larger net charge of $\mathrm{Fe}$ $(0.287)$ and lower Fermi level $(-2.67)$ of $\mathrm{Ni}(\mathrm{Fe})(\mathrm{OH})_{2}-\mathrm{Fe}_{4} \mathrm{~S}_{12}$ suggests a higher adsorption capability to the reaction intermediate. After the electrochemical activation, the net charge of Fe (0.496) and Fermi level $(-2.88)$ of $\mathrm{Ni}(\mathrm{Fe}) \mathrm{OOH}-\mathrm{Fe}_{4} \mathrm{~S}_{12}$ is significantly improved as the surface oxidation. Compared with the electron localization function (ELF) of $\mathrm{Fe}-\mathrm{O}$ bonds $(0.43)$ for $\mathrm{Ni}$
$(\mathrm{Fe})(\mathrm{OH})_{2}$, the incorporation of $\mathrm{S}$ will induce a higher ELF of 0.51 for the $\mathrm{Fe}-\mathrm{S}$ bonds in $\mathrm{Ni}(\mathrm{Fe})(\mathrm{OH})_{2}-\mathrm{Fe}_{4} \mathrm{~S}_{12}$ (Supplementary Fig. $17 \mathrm{c}, \mathrm{d})$, which indicates $\mathrm{Fe}-\mathrm{S}$ bonds are more ionic than $\mathrm{Fe}-\mathrm{O}$ bonds. After the electrochemical activation, the ELF of Fe-S bonds in $\mathrm{Ni}(\mathrm{Fe}) \mathrm{OOH}-\mathrm{Fe}_{4} \mathrm{~S}_{12}$ is further increased to 0.60 . With the increased $\mathrm{S}$ substitution on the surface of $\mathrm{Ni}(\mathrm{Fe}) \mathrm{OOH}$, the gradual electron localization will lead to a further increased ELF of $\mathrm{Fe}-\mathrm{S}$ bonds in the activated $\mathrm{Ni}(\mathrm{Fe}) \mathrm{OOH}-\mathrm{FeS}_{x}$ (Fig. 6c), resulting in more negative charge on the $S$ atoms and more positive charge on the $\mathrm{Fe}$ atoms. Moreover, a stronger hydrogen bond interaction of O-H..S than that of $\mathrm{O}-\mathrm{H}::: \mathrm{O}$ would lead to more charge transfer from $\mathrm{S}$ to $\mathrm{H}$ atoms and more positive charge existed on the $\mathrm{Fe}$ atoms. Therefore, it can improve the bonding between $\mathrm{Fe}$ and ${ }^{*} \mathrm{O}$ intermediate and lead to an enhanced oxygen evolution performance ${ }^{37}$.

\section{Discussion}

In summary, this work presents a microorganism corrosion strategy for preparing highly efficient electrodes towards electrocatalytic water oxidation. The corrosion-formed $\mathrm{Ni}(\mathrm{Fe})$ $\mathrm{OOH}_{-} \mathrm{FeS}_{x}$ electrode manifests excellent activity for oxygen evolution in alkaline electrolyte, requiring an overpotential of only $220 \mathrm{mV}$ to obtain the benchmark current density of $10 \mathrm{~mA}$ $\mathrm{cm}^{-2}$. Experimental results suggest that the synergistic effect between $\mathrm{Ni}(\mathrm{Fe}) \mathrm{OOH}$ and $\mathrm{Fe}-\mathrm{S}$ species would be responsible for this enhanced activity. Theoretical calculations reveal that the rate-determining step of oxygen evolution is the formation of $* \mathrm{O}$ on the $\mathrm{Ni}(\mathrm{Fe}) \mathrm{OOH}-\mathrm{FeS}_{x}$ electrode, the incorporation of $\mathrm{Fe}-\mathrm{S}$ species would enhance the bonding between $\mathrm{Fe}$ and active ${ }^{*} \mathrm{O}$ intermediate and significantly reduce the adsorption free energy 
gap. This work not only provides an efficient electrode for electrocatalytic oxygen evolution but also perhaps more importantly demonstrates an interesting and facile strategy by microorganism-assisted corrosion engineering. This work is a good demonstration that bridges the gap between traditional corrosion engineering and emerging electrochemical energy conversion technologies. Therefore, the present work is likely to stimulate high interest in the multidisciplinary integration among biology, industrial corrosion, nanomaterials design, and modern energy technologies.

\section{Methods}

Microbe cultivation and inoculation. In this study, SRB was isolated from the sludge in Sinopec oilfield, China. Compared with sequences in the GenBank database with BLAST program, SRB belongs to Desulfotomaculum nigrificans $(D$. nigrificans). As a result, SRB seed culture was cultivated separately in different media at $37^{\circ} \mathrm{C}$ (Supplementary Table 1). First, the culture medium was treated and sterilized at $121^{\circ} \mathrm{C}$ for $20 \mathrm{~min}$; Second, vials were inoculated with $100 \mathrm{~mL}$ of seed culture and $1000 \mathrm{~mL}$ of sterile culture, and then incubated at $37^{\circ} \mathrm{C}$. SRB seed culture was obtained after the incubation for 3 day. The initial concentration of SRB inoculum was $8.0 \times 10^{4}$. The amount of SRB ( $\left.V_{\text {microbe }}\right)$ was described as: $V_{\text {microbe }}=\frac{V_{\text {inoculated microbe }}}{V_{\text {inoculated microbe }}+V_{\text {sterile culture }}} \times 100 \%$

Corrosion electrode preparation. $\mathrm{Ni}$ foam $\left(1.0 \times 1.0 \mathrm{~cm}^{2}\right)$ and $\mathrm{Ti}$ sheet $(1.0 \times 1.0$ $\mathrm{cm}^{2}$ ) were pretreated in acetone and ethanol (volume ratio is 1:1) for $30 \mathrm{~min}$ to remove the impurities attached on the electrode surface, then put them into $3.0 \mathrm{M}$ $\mathrm{HCl}$ solution for $15 \mathrm{~min}$ to remove the oxide layers on their surface, and rinsed subsequently with water and ethanol, finally dried with nitrogen gas before use. The corrosion electrode was prepared by putting the pretreated nickel foam into a reagent bottle containing different $V_{\mathrm{SRB}}(23 \%, 33 \%$ and $65 \%)$ of inoculated SRB, then kept them in an anaerobic environment and incubated at $37^{\circ} \mathrm{C}$. Considering the growth curve of SRB, the corrosion time was set to 3 days, 7 days, 10 days, 14 days and 17 days. For comparison, blank Ni foam was treated with the sterile medium at $37^{\circ} \mathrm{C}$ without adding SRB in the corrosion procedure. Furthermore, to investigate the characteristics of pure biofilm, the blank Ni foam was replaced by non-corroding Ti sheets in the same corrosive environment with SRB. After taking out from the SRB corrosion system, the electrodes were rinsed by distilled water and cleaned by absolute ethanol to remove the residual SRB, and dried under a nitrogen gas stream. Similarly, various commercial metal substrates (Fe foam, $\mathrm{Cu}$ foam, Co sheet, NiFe alloy foam, NiCo alloy foam, stainless, carbon steel and $\mathrm{NiFeCu}$ ) as well as reported transition metal compound electrodes (CoP/Cu foam, $\mathrm{CoP} / \mathrm{Fe}$ foam, $\mathrm{FeP} / \mathrm{Fe}$ foam, $\mathrm{Fe}_{2} \mathrm{O}_{3} / \mathrm{Fe}$ foam, NiP/Carbon fiber and $\mathrm{NiFe}-\mathrm{LDH}$ ) were also treated in the SRB corrosion system.

\section{Data availability}

The data that support the findings of this study are available from the corresponding author upon reasonable request.

Received: 22 June 2020; Accepted: 17 September 2020;

Published online: 08 October 2020

\section{References}

1. Wang, Z. L., Xu, D., Xu, J. J. \& Zhang, X. B. Oxygen electrocatalysts in metalair batteries: from aqueous to nonaqueous electrolytes. Chem. Soc. Rev. 43, 7746-7786 (2014).

2. Li, G. et al. Pomegranate-inspired design of highly active and durable bifunctional electrocatalysts for rechargeable metal-air batteries. Angew. Chem. Int. Ed. 55, 4977-4982 (2016).

3. Douka, A. et al. A zeolitic-imidazole frameworks-derived interconnected macroporous carbon matrix for efficient oxygen electrocatalysis in rechargeable zinc-air batteries. Adv. Mater. 32, 2002170 (2020)

4. Fang, W. S. et al. Recent progress on two-dimensional electrocatalysis. Chem. Res. Chin. Univ. 36, 611-621 (2020).

5. Roger, I., Shipman, M. A. \& Symes, M. D. Earth-abundant catalysts for electrochemical and photoelectrochemical water splitting. Nat. Rev. Chem. 1, 0003 (2017).

6. Suen, N. T. et al. Electrocatalysis for the oxygen evolution reaction: recent development and future perspectives. Chem. Soc. Rev. 46, 337-365 (2017).

7. Lu, X. \& Zhao, C. Electrodeposition of hierarchically structured threedimensional nickel-iron electrodes for efficient oxygen evolution at high current densities. Nat. Commun. 6, 6616 (2015).
8. Zhang, B. et al. Homogeneously dispersed multimetal oxygen-evolving catalysts. Science 352, 333 (2016).

9. Wang, Y. et al. Layered double hydroxide nanosheets with multiple vacancies obtained by dry exfoliation as highly efficient oxygen evolution electrocatalysts. Angew. Chem. Int. Ed. 56, 5867-5871 (2017).

10. Yan, Z. et al. Anion insertion enhanced electrodeposition of robust metal hydroxide/oxide electrodes for oxygen evolution. Nat. Commun. 9, 2373 (2018).

11. Huang, Z. F. et al. Chemical and structural origin of lattice oxygen oxidation in Co-Zn oxyhydroxide oxygen evolution electrocatalysts. Nat. Energy 4, 329 (2019).

12. Zhang, P., Lu, X. F., Nai, J., Zang, S. Q. \& Lou, X. W. Construction of hierarchical Co-Fe oxyphosphide microtubes for electrocatalytic overall water splitting. Adv. Sci. 6, 1900576 (2019).

13. $\mathrm{Wu}, \mathrm{T}$. et al. Iron-facilitated dynamic active-site generation on spinel $\mathrm{CoAl} 2 \mathrm{O} 4$ with self-termination of surface reconstruction for water oxidation. Nat. Catal. 2, 763-772 (2019).

14. Roy, C. et al. Impact of nanoparticle size and lattice oxygen on water oxidation on NiFeOxHy. Nat. Catal. 1, 820-829 (2018).

15. Qiu, Z. et al. Direct observation of active catalyst surface phases and the effect of dynamic self-optimization in NiFe-layered double hydroxides for alkaline water splitting.Energy Environ. Sci. 12, 572-581 (2019).

16. Yu, J., Wang, Q., O'Hare, D. \& Sun, L. Preparation of two dimensional layered double hydroxide nanosheets and their applications. Chem. Soc. Rev. 46, 5950-5974 (2017).

17. Chen, G. et al. An amorphous nickel-iron-based electrocatalyst with unusual local structures for ultrafast oxygen evolution reaction. Adv. Mater. 31, 1900883 (2019).

18. Louie, M. W. \& Bell, A. T. An investigation of thin-film Ni-Fe oxide catalysts for the electrochemical evolution of oxygen. J. Am. Chem. Soc. 135, 12329-12337 (2013)

19. Zhang, W., Wu, Y., Qi, J., Chen, M. \& Cao, R. A Thin NiFe hydroxide film formed by stepwise electrodeposition strategy with significantly improved catalytic water oxidation efficiency. Adv. Energy Mater. 7, 1602547 (2017).

20. Yin, S. et al. A highly efficient oxygen evolution catalyst consisting of interconnected nickel-iron-layered double hydroxide and carbon nanodomains. Adv. Mater. 30, 1705106 (2018).

21. Yu, L., Yang, J. F., Guan, B. Y., Lu, Y. \& Lou, X. W. Hierarchical hollow nanoprisms based on ultrathin $\mathrm{Ni}$-Fe layered double hydroxide nanosheets with enhanced electrocatalytic activity towards oxygen evolution. Angew. Chem. Int. Ed. 57, 172-176 (2018).

22. Gong, L. Q. et al. Recent progress on NiFe-based electrocatalysts for alkaline oxygen evolution. Adv. Sustain Syst. 4, 2000136 (2020).

23. Jiang, J. et al. Atomic-level insight into super-efficient electrocatalytic oxygen evolution on iron and vanadium co-doped nickel (oxy)hydroxide. Nat. Commun. 9, 2885 (2018).

24. Schäfer, H. et al. Surface oxidation of stainless steel: sxygen evolution electrocatalysts with high catalytic activity. ACS Catal. 5, 2671-2680 (2015).

25. Schäfer, H. et al. Stainless steel made to rust: a robust water-splitting catalys with benchmark characteristics. Energy Environ. Sci. 8, 2685-2697 (2015).

26. Zou, X. et al. In situ generation of bifunctional, efficient Fe-based catalysts from mackinawite iron sulfide for water splitting. Chem 4, 1139-1152 (2018).

27. Liu, Y. et al. Corrosion engineering towards efficient oxygen evolution electrodes with stable catalytic activity for over 6000 hours. Nat. Commun. 9, 2609 (2018).

28. Liu, H. et al. Corrosion behavior of carbon steel in the presence of sulfate reducing bacteria and iron oxidizing bacteria cultured in oilfield produced water. Corros. Sci. 100, 484-495 (2015)

29. Long, X. et al. Metallic iron-nickel sulfide ultrathin nanosheets as a highly active electrocatalyst for hydrogen evolution reaction in acidic media. J. Am. Chem. Soc. 137, 11900-11903 (2015).

30. Qi, J. et al. Porous nickel-iron oxide as a highly efficient electrocatalyst for oxygen evolution reaction. Adv. Sci. 2, 1500199 (2015).

31. Enman, L. J. et al. Operando x-ray absorption spectroscopy shows iron oxidation is concurrent with oxygen evolution in cobalt-iron (oxy)hydroxide electrocatalysts. Angew. Chem. Int. Ed. 57, 12840-12844 (2018).

32. Sherar, B. W. A. et al. Characterizing the effect of carbon steel exposure in sulfide containing solutions to microbially induced corrosion. Corros. Sci. 53, 955-960 (2011).

33. Trzesniewski, B. J. et al. In situ observation of active oxygen species in Fecontaining Ni-based oxygen evolution catalysts: the effect of $\mathrm{pH}$ on electrochemical activity. J. Am. Chem. Soc. 137, 15112-15121 (2015).

34. Cai, Z. et al. Introducing $\mathrm{Fe} 2+$ into nickel-iron layered double hydroxide: local structure modulated water oxidation activity. Angew. Chem. Int. Ed. 57, 9392-9396 (2018)

35. Tang, C. et al. Energy-saving electrolytic hydrogen generation: Ni2P nanoarray as a high-performance non-noble-metal electrocatalyst. Angew. Chem. Int. Ed. 56, 842-846 (2017). 
36. Xu, X., Song, F. \& Hu, X. A nickel iron diselenide-derived efficient oxygenevolution catalyst. Nat. Commun. 7, 12324 (2016).

37. Wang, T. et al. NiFe (oxy) hydroxides derived from NiFe disulfides as an efficient oxygen evolution catalyst for rechargeable $\mathrm{Zn}$-air batteries: the effect of surface S residues. Adv. Mater. 30, 1800757 (2018).

38. Ali-Löytty, H. et al. Ambient-pressure XPS study of a Ni-Fe electrocatalyst for the oxygen evolution reaction. J. Phys. Chem. C. 120, 2247-2253 (2016).

39. Zhao, Y. et al. Sub-3 nm ultrafine monolayer layered double hydroxide nanosheets for electrochemical water oxidation. Adv. Energy Mater. 8, 1703585 (2018).

40. Gorlin, M. et al. Tracking catalyst redox states and reaction dynamics in $\mathrm{Ni}-\mathrm{Fe}$ oxyhydroxide oxygen evolution reaction electrocatalysts: the role of catalyst support and electrolyte pH. J. Am. Chem. Soc. 139, 2070-2082 (2017).

41. Li, B. Q., Zhang, S. Y., Tang, C., Cui, X. \& Zhang, Q. Anionic regulated NiFe (oxy)sulfide electrocatalysts for water oxidation. Small 13, 1700610 (2017).

42. Wang, M., Dong, C. L., Huang, Y. C. \& Shen, S. Operando spectral and electrochemical investigation into the heterophase stimulated active species transformation in transition-metal sulfides for efficient electrocatalytic oxygen evolution. ACS Catal. 10, 1855-1864 (2020).

43. Friebel, D. et al. Identification of highly active Fe sites in $(\mathrm{Ni}, \mathrm{Fe}) \mathrm{OOH}$ for electrocatalytic water splitting. J. Am. Chem. Soc. 137, 1305-1313 (2015).

\section{Acknowledgements}

This work is supported by the National Natural Science Foundation of China (22075092), the National 1000 Young Talents Program of China, the China Postdoctoral Science Foundation (2018M642810) and the Fundamental Research Funds for the Central Universities (2018KFYXKJC044, 2018KFYYXJJ121, 2017KFXKJC002, 2017KFYXJJ164) are also acknowledged. We thank Prof. X.W.L. and Dr. X.L. very much for their valuable suggestions. We also acknowledge the support of Analytical and Testing Center of Huazhong University of Science and Technology for XRD, Raman, SEM, TEM and XPS measurements.

\section{Author contributions}

B.Y.X. conceived the idea and guided the project. H.Y., L.G., K.Q. and J.W. carried out the sample preparation, physical characterizations and electrochemical measurements.

H.W. carried out the DFT calculations. C.D. performed the XAFS measurements. X.G. and H.L. discussed the experiment results. H.Y. and B.Y.X. discussed and co-wrote the manuscript. All of the authors have commented on the manuscript.

\section{Competing interests}

The authors declare no competing interests.

\section{Additional information}

Supplementary information is available for this paper at https://doi.org/10.1038/s41467 020-18891-x.

Correspondence and requests for materials should be addressed to B.Y.X.

Peer review information Nature Communications thanks the anonymous reviewers for their contribution to the peer review of this work. Peer reviewer reports are available.

Reprints and permission information is available at http://www.nature.com/reprints

Publisher's note Springer Nature remains neutral with regard to jurisdictional claims in published maps and institutional affiliations.

(c) (i) Open Access This article is licensed under a Creative Commons Attribution 4.0 International License, which permits use, sharing, adaptation, distribution and reproduction in any medium or format, as long as you give appropriate credit to the original author(s) and the source, provide a link to the Creative Commons license, and indicate if changes were made. The images or other third party material in this article are included in the article's Creative Commons license, unless indicated otherwise in a credit line to the material. If material is not included in the article's Creative Commons license and your intended use is not permitted by statutory regulation or exceeds the permitted use, you will need to obtain permission directly from the copyright holder. To view a copy of this license, visit http://creativecommons.org/ licenses/by/4.0/.

(C) The Author(s) 2020 